\title{
CORRELATION BETWEEN EMOTIONAL INTELLIGENCE AND PROBLEM SOLVING SKILL OF HEALTH STUDENTS OF FACULTY OF MEDICINE UNIVERSITAS HASANUDDIN
}

\author{
Hasnah $^{1}$, Desy Ana Hendra ${ }^{1}$, Hapsah $^{1}$ \\ ${ }^{1}$ Program Studi Ilmu Keperawatan, Fakultas Keperawatan, Universitas Hasanuddin, Makassar \\ e-mail: hasnah_evhy@yahoo.com; hapsahnsuh@gmail.com
}

\begin{abstract}
Introduction: High demands in all conditions require proffesional health workers. In dealing with patients, health workers need high emotional intelligence and problem solving skills that are qualified to deal with various problems.Objective: To analyze correlation between emotional intelligence with problem solving skill of health student of Faculty of Medicine Universitas Hasanuddin. Method: This quantitative research was conducted in August-September 2017, using observational study designwith cross sectional analytic approach. Population in this research is health students Faculty of Medicine Universitas Hasanuddin who forced in 2013, 2014, 2015, 2016 (N=1995). Sampling technique using cluster random sampling $(\mathrm{n}=333)$. The data were analyzed with Spearman's Rho test.Results: More than half of respondents had a low emotional intelligence $(58.3 \%)$ and medium level of problem solving skill $(51,4 \%)$. Correlation coefficient both of them is weak $(r=0,222 ; p$ value $=0.000<0,05)$. Conclusion: There is a weak correlation between emotional intelligence with problem solving skill of health student of Faculty of Medicine Hasanuddin University. The higher the emotional intelligence of the student, the higher the level of problem solving skill.
\end{abstract}

Keywords:Emotional intelligence, problem solving skills, students

\section{PENDAHULUAN}

Tenaga kesehatan merupakan salah satu profesi yang paling banyak memiliki tuntutan diantara profesi yang lain sebab objek penanganan petugas kesehatan adalah manusia. Salah satu diantara tuntutan tersebut adalah, petugas kesehatan harus tetap profesional disegala kondisi yang dialami pasien. Hal ini membutuhkan kecerdasan emosional yang tinggi bagi petugas kesehatan mengingat kecerdasan emosional dapat berpengaruh dalam lingkungan kerja petugas kesehatan.

Kecerdasan emosi adalah suatu kemampuan untuk mengendalikan emosi dan rasional secara bersamaan dengan kondisi yang tepat (Puspasari, 2010).

Hasil penelitian yang dilakukan oleh Sommaruga, Casu, Giaquinto, \& Gremigni (2016) menemukan bahwa kecerdasan emosional berpengaruh langsung terhadap perawatan yang berpusat pada pasien (PatientCentered Care). Petugas kesehatan seperti perawat, dokter, fisioterapis, asisten perawat, rehabilitator, petugas ambulasi, dan petugas perawatan akut yang memiliki kecerdasan emosional yang baik terbukti dapat berkolaborasi dengan baik dan meningkatkan angka kesembuhan pasien sebesar $63.4 \%$. Penelitian lain menunjukkan bahwa kecerdasan emosional baik yang dimiliki petugas kesehatan dengan salah satu komponennya yakni social skill dapat meningkatkan kemandirian pasien sebesar $42 \%$ (Marks, Horrocks, \& Schutte, 2016).

Kecerdasan emosional terbentuk saat petugas kesehatan masih berada di tahap pendidikan. Hal ini dibuktikan oleh Freshwater \& Stickley (2009), pada mahasiswa perawat kecerdasan emosional terbentuk pada masa perawat tersebut masih 
menjadi mahasiswa. Selain itu juga terdapat penelitian pada mahasiswa kedokteran dan keperawatan di Korea yang menemukan bahwa kecerdasan emosional akan terus berkembang seiring dengan tingkatan mahasiswa di kampusnya (Chun \& Park, 2016).

Mayer, Salovey, Caruso, \& Sitarenios (2006) menjelaskan bahwa kecerdasan emosional dalam pribadi mahasiswa kesehatan terbukti memiliki andil yang besar dalam kemampuan menyelesaikan masalah (Problem Solving Skill). Hal ini dikarenakan mahasiswa kesehatan saat belajar dan menjadi petugas kesehatan nantinya akan dihadapkan dengan berbagai macam emosi manusia sehingga mahasiswa kesehatan harus memiliki kemampuan yang cerdas dalam hal emosionalitas serta cepat dan tegas dalam memecahkan masalah.

Menurut Sharei (2012) kemampuan dalam pemecahan masalah tidak bisa diukur dengan hanya melihat memampuan kognitif seseorang, melainkan harus dengan melihat kemampuan kecerdasan emosionalnya. Ketika terjadi suatu krisis atau masalah, individu yang tidak mampu atau memiliki kecerdasan emosional yang rendah tidak akan mampu mengontrol emosinya sehingga pada saat berkomunikasi tidak akan efektif Deniz (2013).

Rachmat (2009) menjelaskan bahwa banyak faktor yang dapat mempengaruhi kemampuan dalam penyelesaian masalah, dan salah satunya adalah kecerdasan emosi. Dalam menghadapi sesuatu permasalahan, terkadang emosi mewarnai cara berfikir individu sehingga dalam proses berfikir tidak akan efektif. Akibatnya pemecahan masalah akan terhambat. Goleman (2015) mengungkapkan bahwa pemecahan masalah merupakan kombinasi antara pemikiran kreatif dan kecerdasan emosional, karena 80\% kemampuan pemecahan masalah berlandaskan pada kecerdasan emsional, dan 20\% lainnya ditentukan oleh intelegensi.

Hasil studi eksperimental yang dilakukan oleh Palanci \& Okutan (2010) pada mahasiswa di Turki, kecerdasan emosional terbukti dapat meningkatkan Problem Solving Skill, empati, serta kepribadian Mahasiswa. Selain itu, studi tentang membandingkan kecerdasan emosional dengan Problem Solving Skill, dalam menurunkan angka kesembuhan pasien telah diteliti oleh Shahba \& Allahvirdiyani (2013), dengan hasil bahwa kecerdasan emosional dan Problem Solving Skill yang baik dapat meningkatkan angka kesembuhan pasien sebesar $61,2 \%$.

Adapun pada penelitian ini, peneliti ingin membandingkan antara kecerdasan emosional dan problem solving skill pada mahasiswa kesehatan Fakultas Kedokeran Universitas Hasanuddin dengan melihat karakteristik responden seperti usia, jenis kelamin, pengalaman organisasi, program studi, dan tingkat semester.

Oleh sebab itu, terkait dengan pentingnya kecerdasan emosional dalam kemampuan Problem Solving, dan belum terdapatnya institusi kesehatan yang mengidentifikasi pencapaian kecerdasan emosional dan Problem Solving Skill mahasiswa kesehatan, maka peneliti tertarik untuk melakukan penelitian tentang analisis korelasi antara kecerdasan emosional dengan problem solving skill mahasiswa kesehatan fakultas kedokteran Universitas Hasanuddin.

\section{METODE}

Penelitian ini merupakan penelitian kuantitatif dengan menggunakan desain penelitian observasional dan pendekatan analitik cross sectional. Populasi dalam penelitian ini adalah seluruh mahasiswa Program Studi Fakultas Kedokteran Universitas Hasanuddin yang terdiri dari Prodi Pendidikan Dokter, Ilmu Keperawatan, Fisioterapi, Psikologi, dan Kedokteran Hewan yang berjumlah 1995 orang (Data Primer, 
2017).

Teknik sampling yang digunakan dalam penelitian adalah Cluster Random Sampling. Penentuan total sampel dalam penelitian ini menggunakan rumus Slovin. Rumus Slovin yang digunakan pada penelitian ini berdasarkan Sugiyono (2016) yakni:

$$
\mathrm{n}=\frac{\mathrm{N}}{1+\mathrm{N}(\mathrm{e})^{2}}
$$

$$
\begin{aligned}
& \text { Keterangan: } \\
& \mathrm{n}=\text { sampel } \\
& \mathrm{N}=\text { populasi } \\
& \mathrm{e}=\text { interval keyakinan }(0,05)
\end{aligned}
$$

Berdasarkan hasil perhitungan dengan menggunakan rumus tersebut diperoleh estimasi sampel sebanyak 333 orang. Prasetyo (2009) menjelaskan bahwa pengambilan sampel secara proporsional untuk setiap kelompok menggunakan perhitungan sebagai berikut:

$$
n c=\frac{N c}{N} x n
$$

$$
\begin{aligned}
& \text { Keterangan }: \\
& \mathrm{N}=\text { Populasi } \\
& \mathrm{Nc}=\text { Populasi dalam cluster } \\
& \mathrm{n}=\text { sampel } \\
& \mathrm{nc}=\text { sampel dalam cluster }
\end{aligned}
$$

Setelah dilakukan perhitungan, estimasi besar sampel pada masingmasing program studi (PS) adalah: PS. Ilmu Keperawatan $(\mathrm{N}=364, \mathrm{n}=$ 61); PS. Pendidikan Dokter $(\mathrm{N}=834$, $\mathrm{n}=139)$; PS. Fisioterapi $(\mathrm{N}=321$, $\mathrm{n}=53)$; PS. Psikologi $(\mathrm{N}=215, \mathrm{n}=$ 36); PS. Kedokteran Hewan ( $\mathrm{N}=261$, $\mathrm{n}=44$ ). Dari keseluruhan populasi $(\mathrm{N}=1995)$ didapatkan total sampel untuk penelitian ini sebanyak 333 responden.

Kriteria sampel penelitian ini adalah bersedia menjadi responden dan berstatus mahasiswa yang terdaftar aktif di PS. Pada pengumpulan data, responden dipilih sesuai kriteria yang ditentukan, kemudian diberikan informed consent beserta penjelasan mengenai manfaat dan tujuan penelitian. Selanjutnya, peneliti menyebarkan kuesioner kepada responden dan mengumpulkan kembali kuesioner yang telah diisi.

Instrument yang digunakan dalam penelitian ini menggunakan kuesioner. Untuk mengukur kecerdasan emosional digunakan Trait Emotional Intelligence QuestionnaireShort Form (TEIQue-SF). Kuesioner TEIQue-SF merupakan kuesioner paten yang telah dikembangkan oleh Petrides (2009) dan kemudian diterjemahkan ke dalam Bahasa Indonesia oleh peneliti dan telah dilakukan uji validitas nilai cronbach's alpha sebesar 0,781 dan dikatakan reliabel dengan kategori reliabilitas tinggi (Sugiyono, 2016).

Kuesioner untuk menilai problem solving skill mahasiswa terdiri dari 16 butir pertanyaan. Setiap pertanyaan berisikan pertanyaan dengan jawaban berskala 1 sampai dengan 5 . Kuesioner ini diambil dan diterjemahkan kedalam bahasa Indonesia oleh peneliti.

Proses analisis data pada penelitian yaitu analisis univariat yang digunakan untuk mendeskripsikan antara kecerdasan emosional dan problem solving sklill mahasiswa kesehatan fakultas kedokteran Unhas. Analisis bivariate untuk membuktikan ada atau tidaknya hubungan antara kecerdasan emosional dan Problem Solving Skills. Uji statistik yang digunakan pada penelitian ini adalah uji Pearson Corelasi dengan syarat data berdistribusi normal berdasarkan uji skewness pada SPSS dengan derajat kepercayaan 95\% (a = 0,05). Dalam menganalisis data, digunakan data numerik, data kategorik digunakan untuk interpretasi data.

\section{HASIL}

Dilihat dari distribusi frekuensi dengan crosstabulasi untuk mengukur gambaran kecerdasan emosional dan problem solving skill, ditemukan bahwa Kecerdasan emosional dan problem solving skills berdasarkan 
karakteristik responden (tabel 1), kecerdasan emosional (tabel 2), problem solving skil (tabel 3), deskripsi kecerdasan emosional dan problem solving skillberdasarkan karakteristik responden (tabel 4).

\begin{tabular}{|c|c|c|c|c|c|c|c|c|c|c|c|c|}
\hline \multirow{3}{*}{ Karakteristik } & \multicolumn{4}{|c|}{$\begin{array}{c}\text { Kecerdasan } \\
\text { emosional }\end{array}$} & \multicolumn{6}{|c|}{ Problem solving skill } & \multirow{2}{*}{\multicolumn{2}{|c|}{ Total }} \\
\hline & \multicolumn{2}{|c|}{ Tinggi } & \multicolumn{2}{|c|}{ Rendah } & \multicolumn{2}{|c|}{ Tinggi } & \multicolumn{2}{|c|}{ Sedang } & \multicolumn{2}{|c|}{ Rendah } & & \\
\hline & f & $\%$ & $\mathbf{f}$ & $\%$ & $\mathbf{f}$ & $\%$ & f & $\%$ & $\mathbf{f}$ & $\%$ & f & $\%$ \\
\hline \multicolumn{13}{|l|}{ Usia } \\
\hline 17 & 72 & 36.4 & 126 & 63.4 & 91 & 46 & 107 & 54 & 0 & 0 & 198 & 100 \\
\hline $20-36 \mathrm{t}$ & 67 & 49.6 & 68 & 50.4 & 71 & 52.6 & 64 & 47.4 & 0 & 0 & 135 & 100 \\
\hline Total & 139 & 41.7 & 194 & 58.3 & 162 & 48.6 & 171 & 51.4 & 0 & 0 & 333 & 100 \\
\hline \multicolumn{13}{|l|}{ Jenis kelamin } \\
\hline Laki-laki & 23 & 45 & 28 & 55 & 32 & 62.7 & 19 & 37.3 & 0 & 0 & 51 & 100 \\
\hline Peremp & 116 & 41 & 166 & 59 & 130 & 46 & 152 & 54 & 0 & 0 & 282 & 100 \\
\hline Total & 139 & 41.7 & 194 & 58.3 & 162 & 48.6 & 171 & 51.4 & 0 & 0 & 333 & 100 \\
\hline \multicolumn{13}{|l|}{$\begin{array}{l}\text { Pengalaman } \\
\text { organisasi }\end{array}$} \\
\hline Sangat ak & 10 & 47.6 & 11 & 52.4 & 16 & 76.2 & 5 & 23.8 & 0 & 0 & 21 & 100 \\
\hline Aktif & 74 & 41.8 & 103 & 58.2 & 89 & 50.3 & 88 & 49.7 & 0 & 0 & 177 & 100 \\
\hline Kurang aktif & 40 & 53.3 & 35 & 46.7 & 30 & 40 & 45 & 60 & 0 & 0 & 75 & 100 \\
\hline Tide & 15 & 25 & 45 & 75 & 27 & 45 & 33 & 55 & 0 & 0 & 60 & 100 \\
\hline Total & 139 & 41.7 & 194 & 58.3 & 162 & 48.6 & 171 & 51.4 & 0 & 0 & 333 & 100 \\
\hline \multicolumn{13}{|l|}{ Program studi } \\
\hline Keperawatan & 35 & 57.3 & 26 & 42.7 & 29 & 47.5 & 32 & 52.5 & 0 & 0 & 61 & 100 \\
\hline Fisioterapi & 16 & 30.2 & 37 & 69.8 & 29 & 54.7 & 24 & 54.3 & 0 & 0 & 53 & 100 \\
\hline & 16 & 44.4 & 20 & 55.6 & 15 & 41.7 & 21 & 58.3 & 0 & 0 & 36 & 100 \\
\hline Pendidika & 51 & 36.7 & 88 & 63.3 & 72 & 51.8 & 67 & 41.2 & 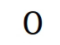 & 0 & 139 & 100 \\
\hline Kedokteran $\mathrm{h}$ & 21 & 47.7 & 23 & 52.3 & 17 & 38.6 & 27 & 61.4 & 0 & 0 & 44 & 100 \\
\hline Total & 139 & 41.7 & 194 & 58.3 & 162 & 48.6 & 171 & 51.4 & 0 & 0 & 333 & 100 \\
\hline \multicolumn{13}{|l|}{ Semester } \\
\hline Semester & 56 & 41.2 & 80 & 58.8 & 69 & 50.7 & 67 & 49.3 & 0 & 0 & 136 & 100 \\
\hline & 24 & 34.6 & 57 & 70.4 & 34 & 42 & 47 & 5 & 0 & 0 & 81 & 100 \\
\hline & 6 & 25 & 18 & 75 & 9 & 37.5 & 15 & 62.5 & 0 & 0 & 24 & 100 \\
\hline 7 & 6 & 24 & 19 & 76 & 13 & 52 & 12 & 48 & 0 & 0 & 25 & 100 \\
\hline Semester 9 & 47 & 70.2 & 29.8 & 33 & 37 & 55.3 & 30 & 44.7 & 0 & 0 & 67 & 100 \\
\hline Total & 139 & 41.7 & 194 & 58.3 & 162 & 48.6 & 171 & 51.4 & 0 & 0 & 333 & 100 \\
\hline
\end{tabular}

Tabel 1. Distribusi Kecerdasan Emosional dan Problem Solving Skill Berdasarkan Karakteristik Responden Mahasiswa Kesehatan Fakultas Kedokteran Universitas Hasanuddin

\begin{tabular}{lcc}
\hline \multicolumn{1}{c}{ Kecerdasan emosional } & f & \% \\
\hline Tinggi & 139 & 41.7 \\
Rendah & 194 & 58.3 \\
\hline Total & $\mathbf{3 3 3}$ & $\mathbf{1 0 0}$
\end{tabular}

Tabe1 2.Tingkat Kecerdasan Emosional Mahasiswa Kesehatan Fakultas Kedokteran Universitas Hasanuddin

\begin{tabular}{lcc}
\hline \multicolumn{1}{c}{ Problem solving skill } & f & \% \\
\hline Tinggi & 162 & 48.6 \\
Sedang & 171 & 51.4 \\
Rendah & 0 & 0 \\
\hline Total & $\mathbf{3 3 3}$ & $\mathbf{1 0 0}$ \\
\hline
\end{tabular}

Tabel 3. Tingkat Problem Solving Skill Mahasiswa Kesehatan Fakultas Kedokteran Universitas Hasanuddin 


\begin{tabular}{|c|c|c|c|c|}
\hline & Median \pm SD & $p$ & $r$ & $95 \% C I$ \\
\hline Kecerdasan emosional & $134 \pm 15,6$ & \multirow{2}{*}{0,000} & \multirow{2}{*}{0,222} & $133-136,4$ \\
\hline Problem solving skill & $58 \pm 5,8$ & & & $57,67-58,93$ \\
\hline
\end{tabular}

Tabel 4.Korelasi antara Kecerdasan Emosional dan Problem Solving Skill Mahasiswa Kesehatan Fakultas Kedokteran Universitas Hasanuddin

\section{PEMBAHASAN}

\section{Kecerdasan emosional}

Kecerdasan emosional adalah kemampuan untuk merasakan, memahami secara efektif, menerapkan daya dan kepekaan emosi sebagai sumber energi, informasi, koneksi dan pengaruh manusia (Agustian, 2005).

Hasil penelitian yang telah dilakukan terhadap 333 responden tentang kecerdasan emosional Mahasiswa Kesehatan Fakultas Kedokteran Universitas Hasanuddin, menunjukkan bahwa lebih dari setengah responden memiliki gambaran kecerdasan emosional yang rendah yakni 194 responden (58,3\%).

Goleman (2015) menyatakan bahwa banyaknya mahasiswa yang memiliki kecerdasan emosional rendah menunjukkan bahwa terdapat masalah saat pembentukan kecerdasan emosional. Kecerdasan emosional yang rendah pada responden memungkinkan adanya proses yang hilang, dimana proses tersebut adalah didalamnya faktor-faktor yang mempengaruhi kecerdasan emosional yang terdiri atas faktor internal dan faktor eksternal. Selain itu faktor eksternal yang meliputi lingkup masyarakat, lingkup pertemanan dan lingkungan akademik merupakan faktor penentu dalam proses pembentukan kecerdasan emosional (Goleman, 2015).

Proses pendidikan sangat berperan dalam pembentukan kecerdasan emosional mahasiswa kesehatan (Shanta \& Gargiulo, 2014). Kecerdasan emosional responden yang rendah mungkin disebabkan oleh adanya proses yang hilang dalam pembentukan kecerdasan emosional pada kerangka konsep dalam masa pendidikan baik dalam masa pembelajaran demi menguasai ilmu pengetahuan dan teknologi, masa pembelajaran dalam penyelesaian masalah, masa pembelajaran dalam membentuk sikap dan tingkah laku professional, masa pembelajaran aktif dan mandiri, dan masa pembelajaran saat berada di dalam masyarakat (Nursalam \& Efendi, 2006).

Kecerdasan emosional memiliki andil yang besar terhadap kinerja petugas kesehatan yang dibentuk selama masa pendidikan. Rendahnya kecerdasan emosional tentunya akan berdampak terhadap kinerja seorang petugas kesehatan nantinya. Smith, Profetto-McGrath, \& Cummings (2011), menyatakan bahwa kecerdasan emosional berpengaruh terhadap leadership dan kemampuan seorang dalam memimpin. Penelitian ini juga sejalan dengan penelitian yang dilakukan oleh Beauvais, Brady, O'Shea, \& Griffin (2011), yang menemukan bahwa petugas kesehatan yang memiliki kecerdasan emosional tinggi memiliki dimensi performa di atas rata-rata yang terdiri atas kepemimpinan, chritical care, kolaborasi, perencanaanevaluasi, hubungan interpersonal dan pengembangan profesional.

Terdapat banyak dampak yang ditimbulkan kedepannya bagi petugas kesehatan yang memiliki kecerdasan emosional yang rendah, namun kecerdasan emosional yang rendah dapat di kembangkan dan ditingkatkan melalui training psikologi dan sosial (Ilievova, Juhasova, \& Baumgartner, 2013). 


\section{Problem solving skill}

Hasil penelitian menunjuk-kan bahwa lebih dari setengah responden atau 171 orang $(51,4 \%)$ memiliki problem solving skill di tingkat sedang. 162 orang $(48,6 \%)$ lainnya memiliki problem solving skill tinggi.

Hal ini menunjukkan bahwa sebagian besar mahasiswa Kesehatan Di Fakultas Kedokteran Unhas memiliki tingkat pemecahan masalah yang sedang. Ini bisa dikarenakan adanya faktor emosional yang mempengaruhi problem solving skill mahasiswa, terlebih lagi dari hasil penelitian ini diperoleh bahwa kecerdasan emosional mahasiswa sebagian besar masih rendah.

Rahmat (2011) mengemuka-kan bahwa ada 4 faktor yang mempengaruhi problem solving skill, yaitu motivasi, kepercayaan dan sikap yang salah, kebiasaan, dan emosi. Hal ini kemungkinan di karenakan mahasiswa dalam menghadapi berbagai situasi biasanya tanpa sadar terlibat secara emosional. Emosi inilah yang akan mewarnai cara berpikir sebagian orang.

\section{Kecerdasan Emosional dan Problem Solving Skill berdasarkan Karakteristik Responden}

Kecerdasan emosional dan problem solving skill berdasarkan usia

Hasil penelitian yang dilakukan pada 333 responden diperoleh bahwa mahasiswa paling banyakmemiliki kecerdasan emosional dan problem solving tinggi adalah responden yang berusia 20 - 36 tahun.

Banyaknya mahasiwa yang berusia remaja dengan gambaran kecerdasan emosional rendah dan tingkat problem solving skill sedang membuktikan bahwa usia berpengaruh terhadap tingkat kecerdasan emosional dan problem solving skill seseorang (Arsana, 2016). Hal ini juga sejalan dengan penelitian yang dilakukan oleh McNulty, Mackay, Lewis, Lane, \& White (2015), yang menemukan bahwa orang yang lebih dewasa memiliki kecerdasan emosional yang lebih tinggi dibandingkan dengan orang dengan usia yang lebih muda. Menurut peneliti, hal ini terjadi dikarenakan kecerdasan emosional akan terus berkembang seiring dengan berkembangnya usia. Semakin bertambahnya usia, maka semakin banyak pula proses pembentuk kecerdasan emosional yang dilalui seseorang.

\section{Kecerdasan emosional dan Problem Solving skill Berdasarkan Jenis Kelamin}

Berdasarkan hasil penelitian, diperoleh bahwa laki-laki memiliki tingkat kecerdasan emosional dan problem solving skill yang lebih tinggi dibandingkan perempuan, yaitu 23 $(45 \%)$ responden memiliki kecerdasan emosional tinggi, dan 32 (62.7\%) responden dengan problem solving skill tinggi. Hal ini sejalan dengan penelitian yang dilakukan oleh McNulty, Mackay, Lewis, Lane, \& White (2015), yang mendapatkan bahwa jenis kelamin lakilaki memiliki kecerdasan emosional dan problem solving skill yang tinggi dibandingkan dengan perempuan. Namun Goleman (2015) menjelaskan bahwa perempuan cenderung memiliki kemampuan unggul dalam menghibur diri, melepaskan kecemasan, dan kemurungan yang ada akibat dari stimulus emosi. Perempuan juga secara mudah mengungkapan apa yang dirasakan, sedangkan laki-laki sebisa mungkin menahan perasaan tersebut agar tidak terlihat lemah (Sutjiato, Kandou, \& Tucunan, 2015).

\section{Kecerdasan emosional dan problem solving skill berdasarkan pengalaman organisasi}

Berdasarkan pengalaman organisasi, mahasiswa yang tergolong aktif ternyata memiliki tingkat kecerdasan emosional yang rendah yaitu $103(58,2 \%)$ responden, namun tingkat problem solving skill mahasiswa yang tergolong sangat aktif 
berorganisasi termasuk dalam kategori tinggi yaitu $16(76,2 \%)$ responden.

Rendahnya tingkat kecerdasan emosional mahasiswa yang aktif dalam berorganisasi mungkin disebabkan dalam pembelajaran di organisasi, seseorang hanya cenderung untuk mengikuti kegiatan organisasi tanpa melihat proses atau pembentukan kecerdasan emosional yang membawa pada nilai yang akan diterapkan pada kehidupan sehari-hari (Dariyo, 2015). Lebih lanjut pula dijelaskan bahwa pada saat berorganisasi, mahasiswa tersebut hanya ikut dalam kegiatan organisasi tetapi tidak berproses.

Tingginya tingkat problem solving skill mahasiswa yang tergolong sangat aktif dalam berorganisasi membuktikan teori Woodcock (2013) bahwa kemampuan berpikir dan kritis, berpikir lateral, penalaran logis, komunikasi, persuasi, negosiasi menjadi kunci kemampuan dalam pemecahan masalah. Semua hal tersebut dapat diperoleh pada saat seseorang sangat aktif dalam berorganisasi.

\section{Kecerdasan emosional dan problem solving skill berdasarkan program studi}

Berdasarkan program studi, diperoleh bahwa fisioterapi memiliki tingkat kecerdasan emosional paling rendah dibandingkan program studi lain yaitu $37(69,8 \%)$ responden, namun meskipun demikian, tingkat problem solving skill mahasiswa fisioterapi lebih tinggi dibandingkan program studi lain yaitu 29 (54,7\%).

Hal ini kemungkinan disebabkan oleh gagalnya proses pembentukan kecerdasan emosional mahasiswa tesebut terkait dengan faktor ekternal yang paling menentukan pembentukan kecerdasan emosional (Goleman, 2015). Berdasarkan hasil analisa, yang menjadi responden mayoritas mahasiswa baru sehingga perbedaan kecerdasan emosional antara program studi tidak lain karena adanya proses dalam pembelajaran klinik yang belum dilalui. Nursalam \& Efendi (2006) mengemukakan bahwa masa pembelajaran demi menguasai ilmu pengetahuan dan teknologi, masa pembelajaran dalam penyelesaian masalah, masa pembelajaran dalam membentuk sikap dan tingkah laku professional, masa pembelajaran aktif dan mandiri, dan masa pembelajaran saat berada di dalam masyarakat harus dilalui untuk meningkatkan kecerdasan emosional. Proses tersebut belum semua dilalui oleh mahasiswa semester awal namun nantinya akan terus bertambah seiring proses pembelajaran yang ada.

\section{Kecerdasan emosional dan problem solving skill berdasarkan tigkat semester}

Berdasarkan tingkat semester, diperoleh bahwa mahasiswa semester 9 memiliki tingkat kecerdasan emosional dan problem solving skill paling tinggi dibandingkan semester-semester dibawahnya yaitu $47(70,2 \%)$ untuk kecerdasan semosional, dan 37 (55,3\%) untuk problem solving skill.

Hasil penelitian membuktikan bahwa semakin tinggi semester maka akan tinggi pula kecerdasan emosional dan tingkat pemecahan masalahnya. Hal ini sejalan dengan penelitian yang dilakukan oleh Shanta \& Gargiulo (2014) yang menemukan bahwa kecerdasan emosional dan problem solving skill mahasiswa senior mengalami perkembangan yang signifikan jika dibandingkan dengan mahasiswa yang baru.

\section{Kecerdasan emosional dan problem solving skill}

Hasil penelitian yang dilakukan oleh 333 responden yang di uji menggunakan Spearman Rho Test diperoleh nilai Sig. (2-tiled) $=0.00$ dengan kekuatan hubungan yang lemah $(r=0,222)$. Hal ini membuktikan bahwa ada korelasi kecerdasan emosional dengan problem solving skill mahasiswa kesehatan Fakultas 
Kedokteran Universitas Hasanuddin. Artinya, semakin tinggi kecerdasan emosionalnya maka semakin tinggi pula kemampuan problem solving mahasiswa tersebut.

Hasil penelitian yang dilakukan oleh Mayer, Salovey, Caruso, \& Sitarenios (2006) juga menunjukkan bahwa kecerdasan emosional merupakan kemampuan untuk mengenali makna emosi dan relasi dari emosi-emosi tersebut dan menggunakan kemampuan tersebut sebagai penalaran dan pemecahan masalah. Kecerdasan emosional dalam pribadi mahasiswa kesehatan terbukti memiliki andil yang besar dalam kemampuan menyelesaikan masalah (Problem Solving Skill). Hal ini dikarenakan mahasiswa kesehatan saat belajar dan menjadi petugas kesehatan nantinya akan dihadapkan dengan berbagai macam emosi manusia sehingga mahasiswa kesehatan harus memiliki kemampuan yang cerdas dalam hal emosionalitas serta cepat dan tegas dalam memecahkan masalah.

Hasil studi eksperimental yang dilakukan oleh Palanci \& Okutan (2010) pada mahasiswa di Turki, juga membuktikan bahwa kecerdasan emosional dapat meningkatkan Problem Solving Skill, empati, serta kepribadian Mahasiswa. Selain itu, studi tentang perbandingan kecerdasan emosional dengan Problem Solving Skill, dalam menurunkan angka kesembuhan pasien telah diteliti oleh Shahba \& Allahvirdiyani (2013), dengan hasil bahwa kecerdasan emosional dan Problem Solving Skill yang baik dapat meningkatkan angka kesembuhan pasien sebesar $61,2 \%$.

Penelitian ini sesuai dengan teori yang dikemukakan oleh Goleman (2015) bahwa pemecahan masalah merupakan kombinasi antara pemikiran kreatif dan kecerdasan emosional, karena 80\% kemampuan pemecahan masalah berlandaskan pada kecerdasan emosional, dan 20\% lainnya ditentukan oleh intelegensi.

\section{SIMPULAN}

Penelitian yang dilakukan tentang analisis korelasi antara kecerdasan emosional dan problem solving skill mahasiswa kesehatan Fakultas Kedokteran Universitas Hasanuddin menunjukkan bahwaadanya korelasi antara kecerdasan emosional dengan problem solving skill mahasiswa kesehatan Fakultas Kedokteran Universitas Hasanuddin. Hal ini dibuktikan berdasarkan hasil uji dengan menggunakan person correlation diperoleh nilai Sig. (2-tiled) $=0.00$. Sehingga dapat disimpulkan bahwa semakin tinggi kecerdasan emosional mahasiswa, maka semakin tinggi pula tingkat problem solving skillnya.

Adapun kekurangan dalam penelitian ini adalah sampel yang digunakan tidak homogen, dan cara menilai keaktifan organisasi dilakukan secara subjektif.

\section{SARAN}

Berdasarkan hasil penelitian, pembahasan dan kesimpulan serta manfaat yang ingin dicapai dalam penelitian ini, maka peneliti mengajukan saran biberbagai bidang seperti bidang pengembangan dan ilmu pendidikan agar bisa menyusun kurikulum dan evaluasi pencapaian soft skill mahasiswa di setiap program studi di Fakultas Kedokteran Universitas Hasanuddin yang berbasis pengembangan kecerdasan emosional, bagi bidang kemahiswaan diharapkan dapat dijadikan acuan rencana program pengembangan kecerdasan emosi melalui banyak kegiatan positif kemahasiswaan, bagi peneliti selanjutnya diharapkan dapat menggunakan sampel yang homogen serta menggunakan kuesioner untuk mengukur tingkat pengalaman berorganisasi terhadap kecerdasan emosional dan problem solving skill, dan bagi mahasiswa dapat mengetahui pencapaian kecerdasan emosional secara pribadi. 


\section{DAFTAR PUSTAKA}

Agustian, A. G. (2005). Rahasia sukses membangun kecerdasan emosional dan spiritual. Jakarta: Arga Tilanta.

Arsana, I. J. (2016). Etika profesi . Yogyakarta: Penerbit Deepublish.

Beauvais, A. M., Brady, N., O'Shea, E. R., \& Griffin, M. T. (2011). Emotional intelligence and nursing performance among nursing students. Nurse Education Today, 396401.

Chun, K. H., \& Park, E. (2016). Diversity of emotional intelligence among nursing and medical students. Osong Public Health Res Perspect, 261-265.

Dariyo, A. (2015). Ketrampilan Organisasi, Kecerdasan Emosi dan Persahabatan. Psychology Forum UMM, 1-7.

Goleman, D. (2015). Emotional Intelligence. Jakarta: PT Gramedia Pustaka Utama.

Foster, K., McCloughen, A., Delgado, C., Kefalas, C., \& Harkness, E. (2015). Emotional intelligence education in pre-registration nursing programmes: An integrative review. Nurse Education Today , 510-517.

Freshwater, D., \& Stickley, T. (2009). The heart of the art: emotional intelligence in nursing education. San Fransisco: Jossey-bass.

Ilievova, L., Juhasova, I., \& Baumgartner, F. (2013). Opportunities for emotional intelligence in context of nursing. Jornal of health science, 20-25.

Lindebaum, D. (2013). Does emotional intelligence moderate the relationship between mental health and job performance? An exploratory study. European Management Journa , 1-6.

Mayer, J., Salovey, P., Caruso, D., \& Sitarenios, G. (2006). Emotional intelligence as a standard intelligence. Washington DC: Delmar Publishers.

Marks, A., Horrocks, K., \& Schutte, N. (2016). Emotional intelligence mediates the relationship between insecure attachment and subjective health outcomes. Personality and Individual Differences, 188-192.

McNulty, J., Mackay, S., Lewis, S., Lane, S., \& White, P. (2015). An international study of emotional intelligence in first year. Radiography xxx, 1-6.

Nursalam, \& Efendi, F. (2006). Pendidikan dalam keperawatan. Jakarta: Salemba
Medika.

Othman, C. N., Yusof, M. S., Md Din, A. \& Zakaria, L. A. (2016). emotional intelligence and personality traits in relation to psychological health among pharmacy students in malaysia. Social and Behavioral Sciences, $253-262$.

Palanci, M., \& Okutan, M. (2010). Explanation of school administrators' problem solving skills with their personality traits, emotional intelligence and emphatic tendency. Procedia Social and Behavioral Sciences 9 , 1993-1997.

Petrides, K. (2009). Psychometric properties of the trait emotional. The Springer Series, $1-5$.

Prasetyo, B. (2009). Metode penelitian kuantitatif. Jakarta: PT RajaGrafindo Persada.

Puspasari, A. (2010). Emotional intelligent parenting. Jakarta: Elex Media Komputindo.

Shahba, S., \& Allahvirdiyani, K. (2013). Comparative study of problem-solving and emotional intelligence on decreasing of third grade girl students' aggression of the rajaee guidance school of tehran. Social and Behavioral Sciences, $778-780$.

Shanta, L., \& Gargiulo, L. (2014). A study of the influence of nursing education on development of emotional intelligence. Journal of Professional Nursing, 516-517.

Sharei, M. (2012). Investigation the effect of emotional eintelligence skills and metakognitive capabilities on student's methematical problem solving. Educational Research.

Smith, K. B., Profetto-McGrath, J., \& Cummings, G. G. (2011). Emotional intelligence and nursing: An integrative literature review. International Journal of Nursing Studies, 1624-1636.

Sommaruga, M., Casu, G., Giaquinto, F., \& Gremigni, P. (2016). Self-perceived provision of patient centered care by healthcare. Patient Education and Counseling, 1-6.

Sugiyono. (2016). Statitstika untuk penelitian. Bandung: Penerbit Alfabeta.

Woodcok, B. (2013). Problem solving and anayitical skills. Retrieved Januari 26, 2017, from University of KEnt: http:// www.kent.ac.uk/careers/sk/problemsolving-skills.htm 